\title{
Triglycerides, cholesterol, and phospholipids in normal heart papillary muscle and in patients suffering from diabetes, cholelithiasis, hypertension, and coronary atheroma
}

\author{
M. AlavaikKo, Rittta ElfVing, J. hirVONEN, AND J. JärVi \\ From the Departments of Pathology and Forensic Medicine, University of Oulu, Oulu, Finland
}

SYNOPSIS The triglyceride, cholesterol, and phospholipid contents of heart papillary muscle were measured in groups of obviously healthy and diseased females and males on whom either routine or forensic necropsies were performed. In healthy men the triglyceride content was $1.77 \pm 1.30$ $\mathrm{mg} / \mathrm{g}$ of wet weight and in women $1.25 \pm 0.48 \mathrm{mg} / \mathrm{g}$ wet weight. The corresponding values for cholesterol were $1.07 \pm 0.24 \mathrm{mg} / \mathrm{g}$ and $1.21 \pm 0.22 \mathrm{mg} / \mathrm{g}$ and those for phospholipids $17 \cdot 70 \pm 5 \cdot 15$ $\mathrm{mg} / \mathrm{g}$ and $19 \cdot 65 \pm 10 \cdot 21 \mathrm{mg} / \mathrm{g}$. The differences between the sexes were not significant.

The hypertensive or cardiac hypertrophy group had about the same or slightly lower means for lipid content.

In the cholelithiasis group, women had significantly high triglyceride values $(3 \cdot 38 \pm 2 \cdot 36 \mathrm{mg} / \mathrm{g})$. The cholesterol values were not significantly elevated in either men or women.

In the diabetic group, triglycerides were significantly increased both in men (mean $8 \cdot 12 \pm 0.54$ $\mathrm{mg} / \mathrm{g})$ and in women $(6.85 \pm 5.66 \mathrm{mg} / \mathrm{g})$. The cholesterol mean values were also high in both sexes, but the rise was not significant because of the great variation.

In the coronary atheroma group, both male and female hospital cases had high triglyceride contents (mean $4.48 \pm 4.25 \mathrm{mg} / \mathrm{g}$ and $3.65 \pm 3.94 \mathrm{mg} / \mathrm{g}$ ) whereas the forensic cases had only slightly elevated or normal values. Cholesterol assays paralleled the triglyceride ones, but phospholipids showed an inverse trend.

The results showed that the lipid content of papillary muscle was increased in diseases where disturbances of lipid metabolism are evident, as in diabetes and cholelithiasis. In coronary atheroma only those cases with advanced obstruction of the arteries were associated with abnormal values of papillary lipids. No increase of the lipid content with age alone was found, nor was there any correlation with obesity.

It was found in previous investigations that Oil Red O-positive material accumulated in the cardiac papillary muscle and its arterioles to a greater extent in diseases associated with coronary atheroma such as diabetes mellitus and gallstones (Alavaikko, Hirvonen, and Räsänen, 1970). In further studies the lipid material was analysed both histochemically and by thin-layer chromatography. Histochemical staining revealed that triglycerides were present in the papillary muscle cells in cases of diabetes and coronary atheroma. Cholesterol was found in cholelithiasis cases in the chorda tendineae and arteriolar walls. No pathological accumulation of Received for publication 19 February 1973. phospholipids was demonstrable by histochemical means (Alavaikko and Hirvonen, 1971).

The histochemical findings prompted us to undertake quantitative analyses of the lipid content of papillary muscle. It was necessary to collect papillary muscle also from healthy persons, because knowledge of the amount of lipid in normal cardiac muscle is scanty. Some information was available on the normal content of phospholipids and cholesterol (Documenta Geigy, 1960) in the human heart, and two reports of triglycerides in the heart muscle were found (Wheeldon, Schument, and Turner, 1965; Lindlar and Zaki, 1966).

The object of the present investigation was to 
determine whether there is an accumulation of lipids in cardiac papillary muscle in diseases known to be associated with disturbances in lipid metabolism. Triglycerides, cholesterol, and phospholipids were selected to represent the main lipid classes. The results were compared with a reference group consisting of obviously healthy persons who died violently.

\section{Material}

The material consisted of anterior papillary muscle collected from necropsies in the Departments of Pathology and Forensic Medicine. Patients who died in the hospital numbered 62 and the same number had suffered a violent death. In the last mentioned cases the agonal period was less than one hour. The corpses were stored in the cold $\left(+4^{\circ} \mathrm{C}\right)$ and necropsy was performed within one to three days after death. None of the corpses showed autolysis. After excision the sample was quick frozen in liquid nitrogen and stored at $-25^{\circ} \mathrm{C}$ until analysed.

Before the material was divided into the various groups the possible effect of obesity on the lipid content was checked. Thickness of abdominal subcutaneous fat had been measured at thenecropsy. There was no correlation of obesity with the papillary lipid values either in forensic or hospital cases. Distribution of high and low values showed no trend in the group of cases with 1-2 cm thick fat layer and in that with $3-4 \mathrm{~cm}$ of fat or more.

\section{DISEASE GROUPS}

The hospital and forensic material was divided into the following disease groups in accordance with the earlier histochemical studies:

\section{Hypertension or cardiac hypertrophy}

Criteria of two kinds were used for this group; clinically diagnosed hypertension, and the presence of left cardiac hypertrophy at necropsy (heart weight over $400 \mathrm{~g}$ ) without valvular lesions. None of these suffered from coronary sclerosis, cholelithiasis, or diabetes.

\section{Cholelithiasis}

Gallstones were found at necropsy.

\section{Diabetes mellitus}

Clinically diagnosed diabetes.

\section{Coronary atheroma}

Verified at necropsy and divided into two grades: (a) mild, soft endothelial plaques with no obstruction of the lumen, and $(b)$ severe, calcified plaques with obstruction of the lumen.
Cases with more than one disease were at first $\frac{0}{\overrightarrow{0}}$ studied separately. In the final analysis, however, $\frac{}{-}$ these cases were classified according to the disease $\overrightarrow{\vec{N}}$ which seemed to affect the muscle lipid content. For instance, cases with both cholelithiasis and hypertension were finally placed in the cholelithiasis group, because hypertension alone had no significant effect on the papillary lipid values.

\section{REFERENCE MATERIAL}

The patients who had died from violence and had no disease served as a reference or control group. The causes of death included drowning, hanging, and severe crushing. As mentioned, cases with an agonal period of more than one hour were not accepted so $\mathcal{O}$ that agonal metabolic disturbances which might $\rightarrow$

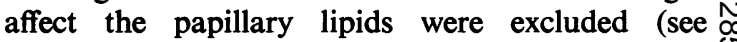
Alavaikko et al, 1970). Those with disease were the same as in the hospital series. The mean values for triglycerides, cholesterol, and phospholipids served as reference values with which the results from the disease groups were compared.

\section{Methods}

\section{EXTRACTION OF LIPIDS}

The papillary muscle sample was weighed and homogenized in a chloroform-methanol mixture $(2: 1)$ (Folch, Lees, and Stanley, 1957). The final ratio of tissue and solvent was adjusted to $1: 20$. The homogenate was filtered and washed through the filter with one fifth vol of $0.9 \%$ saline. The chloroform phase was separated and if turbid was cleared by adding a few drops of methanol. Thereafter the volume of chloroform was diluted to the original $1 \mathrm{~g}$ 웅 of tissue to $20 \mathrm{ml}$ of solvent. The lipid assays were carried out on this chloroform extract.

TRIGLYCERIDES (TG)

Glycerides were first saponified and the glycerol 웅 formed was oxidized to formaldehyde which was $>$ treated with diacetyl-acetone and ammonia to form a fluorescent compound, 3.5-diacetyl-1.4- $\bar{N}$ dihydrolutidine. This compound was assayed $\%$ fluorometrically according to the method of Kessler $N$ and Lederer (1965).

\section{CHOLESTEROL (CHOL)}

The colorimetric method of Levine, Morgenstern, $\stackrel{0}{\frac{C}{\infty}}$ and Vlastelica (1967) based on the Liebermann re- $\stackrel{\infty}{?}$ action with acetic acid, acetic anhydride and $\square$ sulphuric acid was used.

\section{PHOSPHOLIPIDS (PL)}

The Biochemica test combination package TC-PH, No 15920 TPAC was used. The organic phosphate 
in the lipid extract was corrected by incineration into inorganic phosphate, which was assayed colorimetrically (Zilversmit and Davis, 1950).

\section{STATISTICAL ANALYSIS}

The results were treated with Mann-Whitney's $\mathrm{U}$ test, which is more suitable than the $t$ test for data with a large standard deviation (Siegel, 1956).
Results

The results are given as the mean for this group \pm 1 SD.

THE CONTROL GROUP OR HEALTHY CASES

It was found that the mean triglyceride concentration was higher in men than in women, the values being

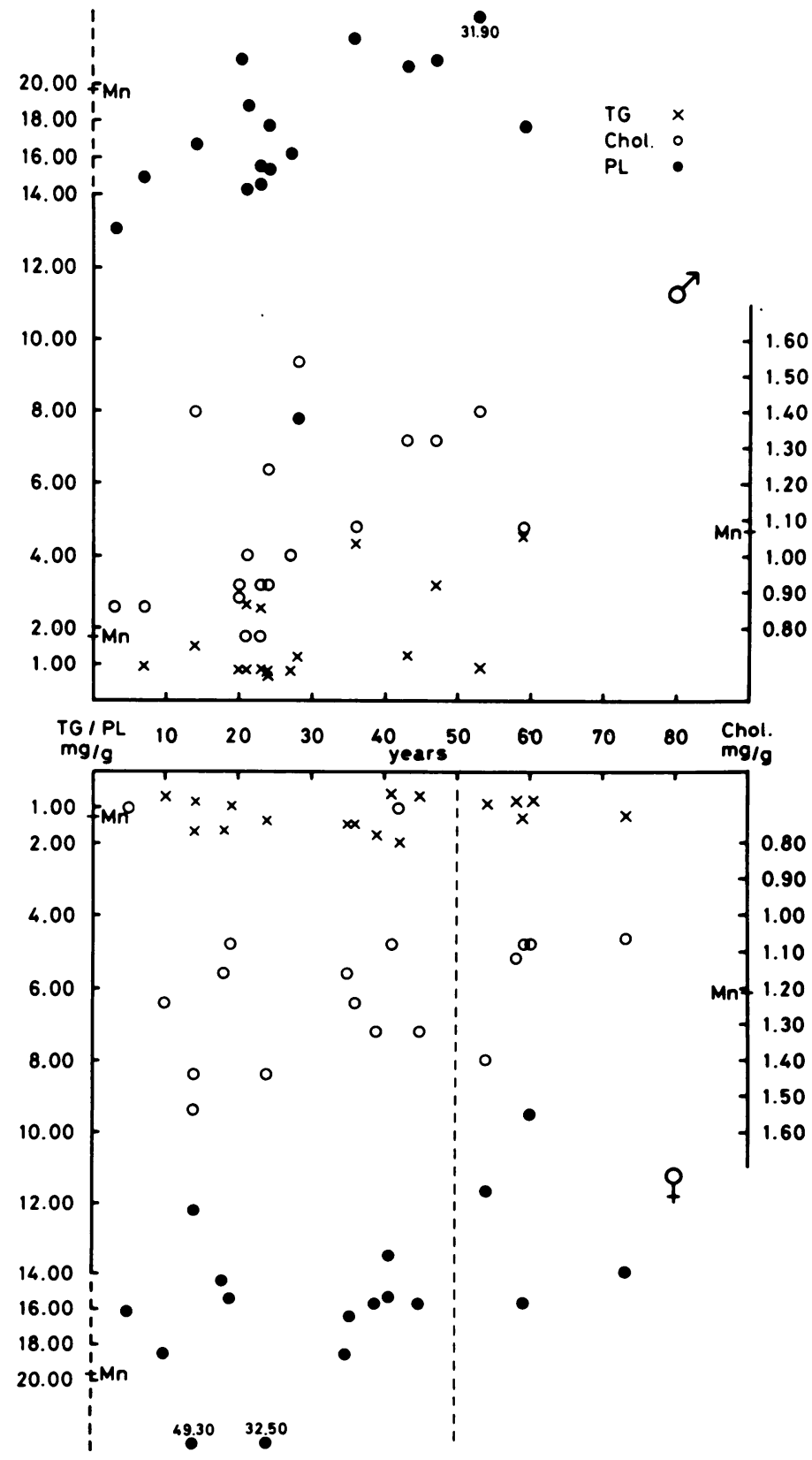

Fig 1 Triglyceride (TG), cholesterol (Chol), and phospholipid (PL) values of papillary muscle in the normal or reference group. Every case is illustrated separately with three signs on one vertical line on the age abscissa. Mean values (Mn) are marked on the ordinate. The forensic groups of older women with mild coronary sclerosis or cardiac hypertrophy (right from the dashed line) have been added since no females aged more than 50 years without any disease could be found. No trend of the lipid values is demonstrable with age. 


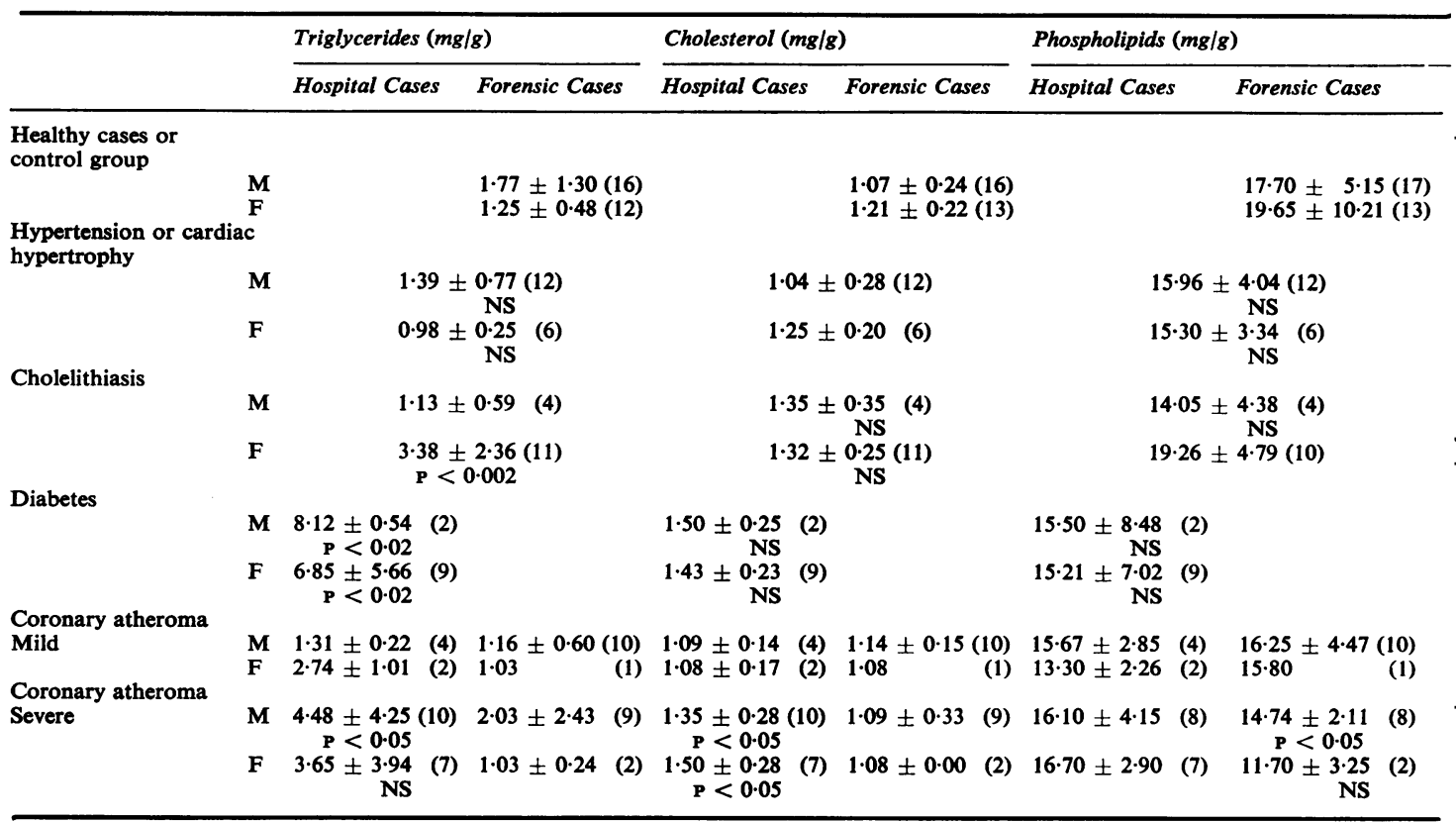

Table Mean values and standard deviations of triglyceride (TG), cholesterol (Chol), and phospholipid (PL) values in the different groups

The amount of lipid is expressed as $\mathrm{mg} / \mathrm{g}$ of wet weight of tissue. The statistical significance of the differences between the disease group and the control group was calculated with the Mann-Whitney $U$ test. The number of patients in each group is given in parentheses after the mean value. The significance of the change is given below the mean.

$1.77 \pm 1.30 \mathrm{mg} / \mathrm{g}$ and $1.25 \pm 0.48 \mathrm{mg} / \mathrm{g}$ respectively. The cholesterol $(1.07 \pm 0.24 \mathrm{mg} / \mathrm{g}$ and $1.21 \pm 0.22$ $\mathrm{mg} / \mathrm{g})$ and phospholipid $(17 \cdot 70 \pm 5.15 \mathrm{mg} / \mathrm{g}$ and $19.65 \pm 10.21 \mathrm{mg} / \mathrm{g}$ ) values were on average higher in women (see table). None of the sex differences, however, were statistically significant. The lipid concentration in men seemed generally to rise slightly with age, but not in the hypertension or mild coronary atheroma group, which showed patients aged 70-80 years with normal values. No trend of elevation with age was observed in women either (fig 1). A few very high values for phospholipids (over $30 \mathrm{mg} / \mathrm{g}$ ) were encountered both in men and women (fig 1).

\section{HYPERTENSION AND CARDIAC HYPERTROPHY} GROUPS

A slight decrease $(28 \%)$ of the phospholipid value was observable in women, but it was not significant by the $U$ test. The cholesterol concentrations were similar to those in the control group (see table). The average triglyceride values were low in both sexes $1.39 \pm 0.77 \mathrm{mg} / \mathrm{g}$ (= lower by $21 \%$ than in the controls) in females. However the differences from normal were not statistically significant.

\section{CHOLELITHIASIS GROUP}

The level of triglyceride was superficially increased in women $(P<0.002)$, the mean being $3.38 \pm 2.36$ $\mathrm{mg} / \mathrm{g}$, ie, higher by $170 \%$ than in the control group. The triglyceride content in men did not differ from that of the controls. The mean cholesterol values in men and women were slightly elevated, but the changes were not significant (see table). Phospholipids o were about equal to the control values. The lipid $\tilde{O}$ contents did not vary significantly with age (fig 2 ).

DIABETIC GROUP

Triglycerides were significantly $(P<0.02)$ increased both in men (mean $8.12 \pm 0.54 \mathrm{mg} / \mathrm{g}$ ) and in women $(6.85 \pm 5.66 \mathrm{mg} / \mathrm{g})$ (see table). The cholesterol mean $\square$ values were also elevated by $43 \%(1.50 \pm 0.25 \mathrm{mg} / \mathrm{g})$ in men and by $18 \%(1.43 \pm 0.23 \mathrm{mg} / \mathrm{g})$ in women, but the changes were not significant because of the great variation. In women, phospholipids were lower by $23 \%(15 \cdot 21 \pm 7.02 \mathrm{mg} / \mathrm{g})$ than the reference 


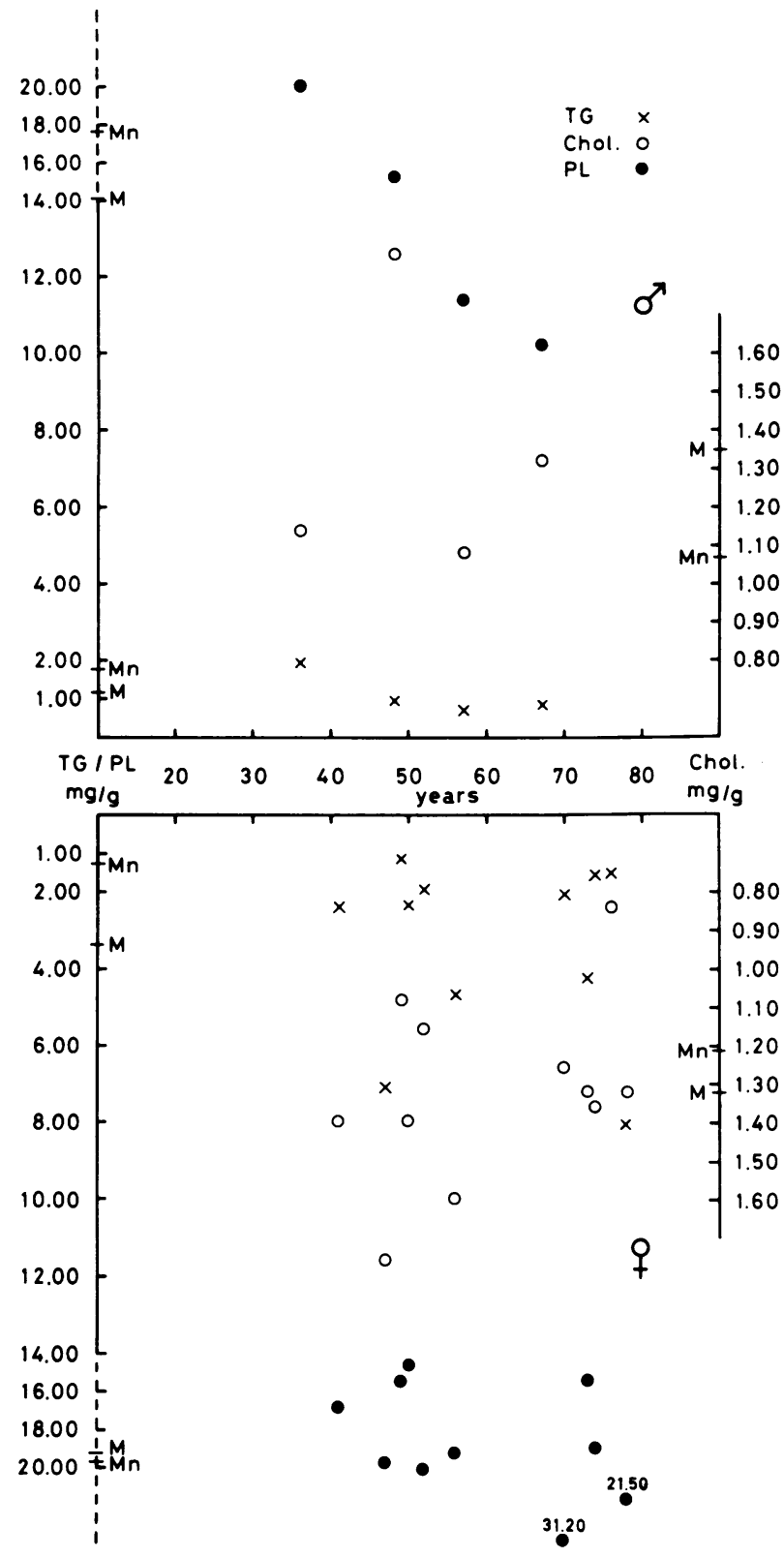

Fig 2 Lipid values of the papillary muscle in cholelithiasis cases. Every case has three signs on the same vertical line. The mean $(\mathrm{M})$ and normal mean $(\mathrm{Mn})$ are marked on the ordinate. Cholesterol values are high in many cases, but the mean value does not differ significantly from the control. Triglycerides were significantly elevated in women (U test, $\mathrm{P}<0.002)$.

value, but the difference was not significant. The lipid contents did not show any general trend attributable to age (fig 3 ).

MILD CORONARY SCLEROSIS

Lipid concentrations were about the same as in the control material. The only group showing possible deviation was that of the female hospital cases: triglycerides were higher by $119 \%(2.74 \pm 1.01$ $\mathrm{mg} / \mathrm{g})$ and phospholipids lower by $32 \%(13.30 \pm 2.26$ $\mathrm{mg} / \mathrm{g}$ ) than the reference values. The number of cases in this group was only two, but the trend is the same as that seen more definitely in the severe coronary atheroma cases (see also fig 1 , females). 


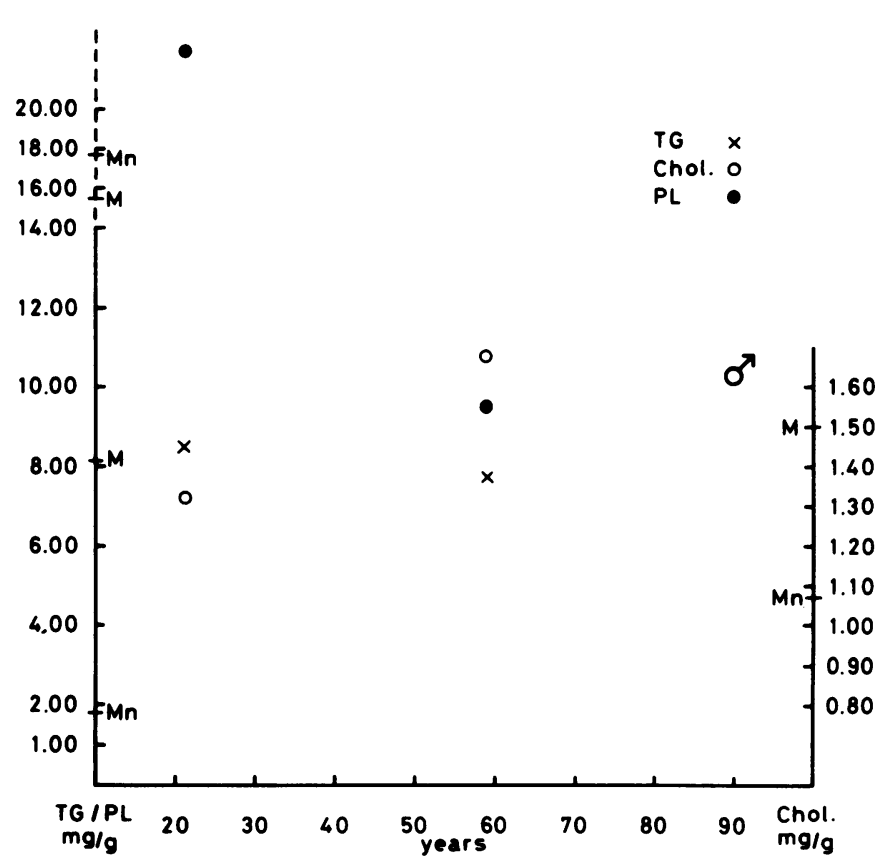

Fig 3 Lipid values of the papillary muscle in diabetic patients. The mean $(\mathrm{M})$ and normal mean (Mn) are marked on the ordinate. Note the significantly increased mean value for triglycerides in both sexes $(\mathrm{P}<0.02)$. Elevation of cholesterol mean values was not significant. The trend of low phospholipid content is also noticeable in individual cases.

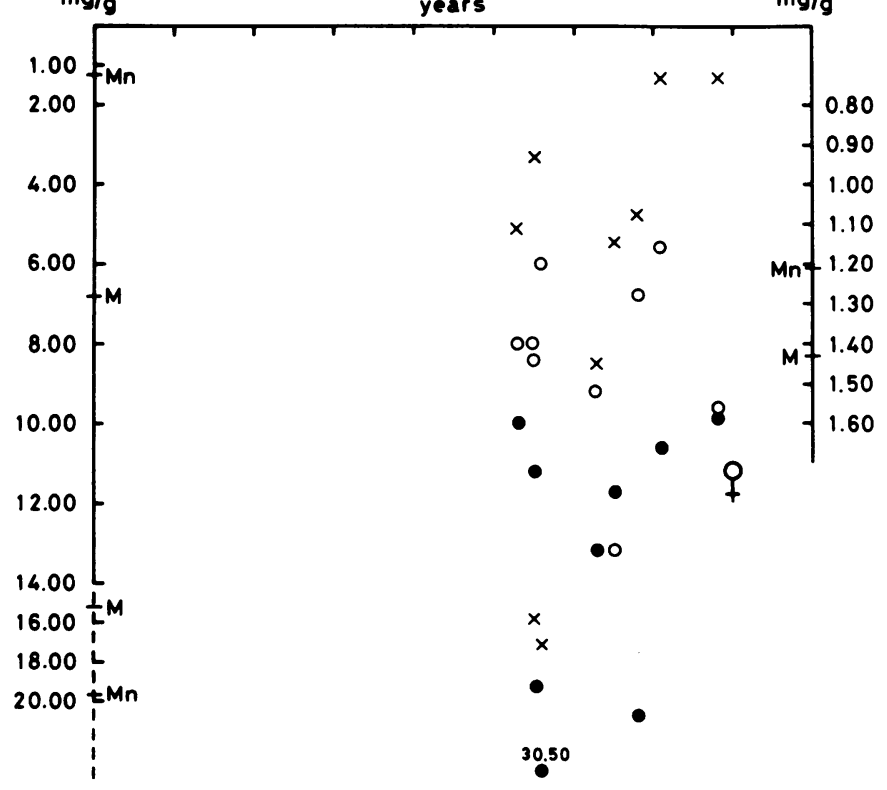

SEVERE CORONARY ATHEROMA

Several abnormal lipid values were found in this group (see table). The mean triglyceride concentration of the male hospital cases was $4.48 \pm 4.25 \mathrm{mg} / \mathrm{g}$, an increase of $153 \%$, which was statistically almost significant $(P<0.05)$. There were two female hospital cases with very high triglyceride values

causing the mean value to be higher by $192 \% \stackrel{\text { ? }}{+}$ $(3.65 \pm 3.94 \mathrm{mg} / \mathrm{g})$ than the reference, but because of the large variation in the group the change was not significant (fig 4). Among the forensic cases only one man had an increased triglycerides value which $\mathbb{\Omega}_{\AA}$ was as high as $8 \mathrm{mg} / \mathrm{g}$.

In the group of hospital cases, the mean values for 


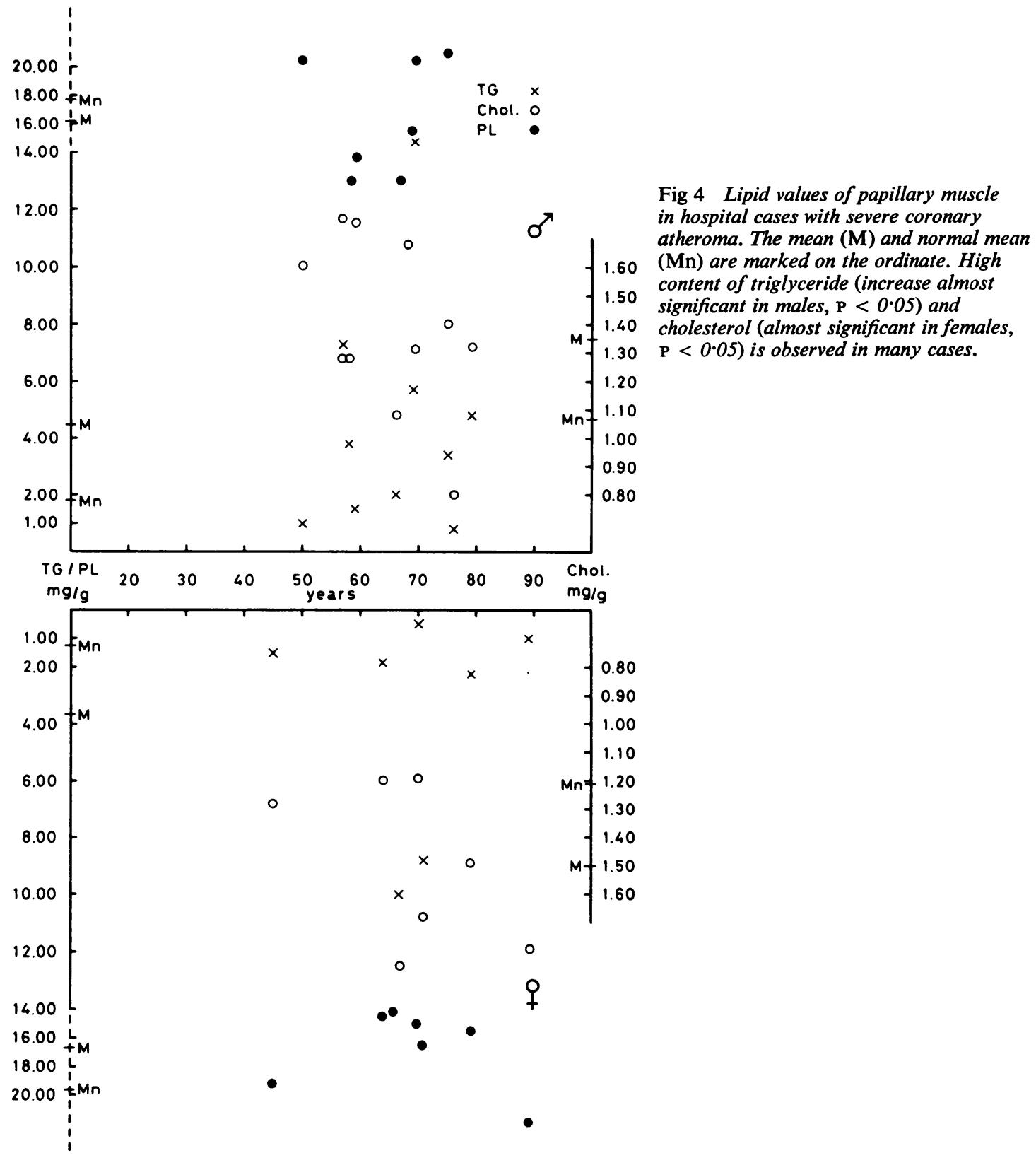

cholesterol were $1.35 \pm 0.28 \mathrm{mg} / \mathrm{g}$ in men (an increase of $26 \%$ ) and $1.50 \pm 0.28 \mathrm{mg} / \mathrm{g}$ in women (an increase of $24 \%$. The changes were almost significant $(P<0.05)$. In the forensic series, cholesterol was within the normal limits. The means for phospholipid were slightly lower in the forensic group both in men $(14.74 \pm 2.11 \mathrm{mg} / \mathrm{g})$ and in women $(11 \cdot 70 \pm$
$3 \cdot 25$, two cases). The decrease of $17 \%$ in men was almost significant $(P<0.05)$.

\section{Discussion}

Lipid analysis of postmortem samples involves several factors which cause difficulties in the com- 
parison of results obtained by different investigators. Comprehensive reviews of the clinical, postmortem, and technical variables are given in the articles of Khan, Cox, and Asdel (1963) and Lindlar and Zaki (1966). The amounts of lipid in cardiac papillary muscle obtained in the present study are within the same range as those reported in most previous studies (Khan et al, 1963; Lindlar and Zaki, 1966; Nieminen, 1967). As to the amount of triglycerides in the heart, Wheeldon et al (1965) reported triglyceride values as high as $7.8 \mathrm{mg} / \mathrm{g}$ (converted from $8.9 \mathrm{mmol} / \mathrm{kg}$ ) in the ox heart. Their sample was a whole heart ventricle which probably contained more adipose tissue on average than does the papillary muscle. Cholesterol and phospholipid values were within the same range as in the present analysis. Autolysis might have affected the present results of triglyceride assays, although this is unlikely, since little lipid breakdown occurs in the myocardium for the first two days after death (Lindlar and Zaki, 1966). Variation of water content might affect the results, because the amount of water in tissues depends on the agonal factors.

Earlier histochemical reports have made it clear that the fatty change of the myocardium is due to accumulation of neutral lipids (eg, Lindlar and Zaki, 1966). In a histochemical analysis of a part of the present material it was found that the papillary muscle arteries and chorda tendineae mainly take up cholesterol esters (Alavaikko and Hirvonen, 1971; Alavaikko and Hirvonen, 1973). Fatty changes in these tissue components did not correlate with the grade of extramural coronary atheroma, but factors predisposing to coronary atheroma-diabetes, cholelithiasis, and the climacteric-seemed to be of more importance (Alavaikko et al, 1970).

The increased amount of triglyceride in our diabetes group is consistent with our histochemical observations and is probably due to diabetic lipaemia. A distinct increase of triglycerides was also found in hospital cases with severe coronary atheroma, but such a rise was not observed in the forensic cases of equal severity. Possibly, coronary sclerosis must be so far advanced that cardiac dysfunction follows before accumulation of lipids begins in the muscle. The coronary atheroma patients who died in hospital were patients who had this disease as the primary cause of death, whereas the forensic cases were able to live normal lives indicating good cardiac function. Utilization of exogenous triglycerides by the myocardium is suppressed in hypoxaemic conditions (Yasuda, 1968), and this fact partly explains the increased accumulation of triglyceride in severe coronary atheroma. The finding that papillary triglycerides were also high in female cholelithiasis patients agrees well with the earlier histochemical observations. Accumulation of lipids generally (Alavaikko et al, 1970), and of triglycerides more specifically (Alavaikko and Hirvonen, 1973) was noticed in the myocardial parenchyma and arteriolar walls. High content of triglyceride in the myocardium of cholelithiasis cases may be attributed to hyperlipaemia resulting from a lipid metabolic error and/ or dietary factors. Obesity as such was found to have no effect on the lipid values in this material.

Low levels of triglyceride in our present hypertension or cardiac hypertrophy group were somewhat inconsistent with our earlier histochemical studies which revealed moderate fatty change in hypertonic cases with Oil Red O staining (Alavaikko et al, 1970). The material of the two studies was derived from different cases and the methods are not comparable, which may explain the discrepancy. The low level of triglycerides may be due to the increased demands of fuelling the strained myocardium in hypertension.

It was concluded from our histochemical studies that an abundance of cholesterol esters accumulates in the chorda tendineae and arterioles of patients with diabetes or gallstones. Cholesterol and phospholipids are normal structural lipids in the myocardial cells and do not participate in myocardial fatty change (Lindlar and Zaki, 1966; Alavaikko and Hirvonen, 1973). The variation in cholesterol and phospholipid values noted in the present study can be partly due to variation in water content. Another factor is also likely to have affected the results, namely, disintegration of muscle cells and increase of scar tissue in the papillary muscle. Degenerative changes are particularly common in the papillary muscle (Brand, Brown, and Berge, 1969). The observation that phospholipid tended to be low in the disease groups, especially in the ones with pathologically high triglyceride values, can be explained by disintegration of muscle cells. Cholesterol values showed an opposite trend. Slightly elevated concentrations were found in diabetes, cholelithiasis, and the severe coronary atheroma of hospital cases. One of our histochemical findings was that cholesterol esters accumulate in the chordae and arterioles of patients suffering from these illnesses. The increase of cholesterol values was not statistically significant in the present study, apparently because the pathological or nonstructural cholesterol represents only a small proportion of the total papillary cholesterol.

The authors thank Mr Esko Vakkilainen, BSc, for his valuable help in performing the statistical analysis. 


\section{References}

Alavaikko, M., and Hirvonen, J. (1971). Histochemical studies of lipids accumulating in human cardiac papillary muscle. (Abstr.) Scand. J. clin. Lab. Invest., 27, Suppl. 116, 14.

Alavaikko, M., and Hirvonen, J. (1973). Histochemical investigations of lipids in human heart papillary muscle. Histochem. J., in press.

Alavaikko, M., Hirvonen, J., and Räsänen, O. (1970). Fatty change in papillary heart muscle and in its arterioles. Analysis of a material of 262 autopsies. Acta path. microbiol. scand., Sect. A, 78, 458-472.

Brand, F. R., Brown, A. L., Jr., and Berge, K. G. (1969). Histology of papillary muscles of the left ventricle in myocardial infarction. Amer. Heart J., 77, 26-32.

Documenta Geigy (1960). Wissenschaftliche Tabellen 6th ed., edited by K. Diem. Geigy A.G., Basle.

Folch, J., Lees, M., and Stanley, G. H. S. (1957). A simple method for the isolation and purification of total lipides from animal tissues. J. biol. Chem., 226, 497-509.

Kessler, G., and Lederer, M. (1966). Fluorometric measurements of triglycerides. In Automation in Analytical Chemistry. (Technicon Symposia 1965). Mediad, White Plains, N.Y., New York.
Khan, B., Cox, G. E., and Asdel, K. (1963). Cholesterol in human tissues: new considerations. Arch. Path., 76, 369-381.

Levine, J., Morgenstern, S., and Vlastelica, D. (1967). A direct Liebermann-Burchard method for serum-cholesterol. (Technicon Symposia, 1965-67) Vol. 1, p. 25.

Lindlar, F., and Zaki, I. A. (1966). Lipidchemische Untersuchungen zur Frage der degenerativen Myokardverfettung. Virchows Arch. path. Anat., 341, 142-147.

Nieminen, E. (1965). Free and esterified cholesterol in human organs and tissues. Ann. Acad. Sci. fenn. V Medica, 118, 1-104.

Siegel, S. (1956). Non-Parametric Statistics for the Behavioral Sciences, p. 116. McGraw-Hill, New York; Kogakuska, Tokyo.

Wheeldon, L. W., Schumert, Z., and Turner, D. A. (1965). Lipid composition of heart muscle homogenate. J. Lipid Res., 6, 481-489.

Yasuda, K. (1968). Metabolic studies on human myocardium in vivo; Lipid metabolism and its responses to acute induced hypoxemia (1) Myocardial lipid metabolism during room air respiration, (2) Myocardial lipid metabolism during acute induced hypoxemia (Japanese). Jap. circulat. J., 32, 1621-1646.

Zilversmit, D. B., and Davis, A. K. (1950). Microdetermination of plasma phospholipids by trichloroacetic acid precipitation. J. Lab. clin. Med., 35, 155-160. 